\title{
Correlation between Estimated Fetal Weight at Term by Ultrasonogram and Actual Birth Weight
}

\author{
NR SHAPLA $^{\mathrm{a}}$, MA ALEEM ${ }^{\mathrm{b}}$, E JESMIN ${ }^{\mathrm{c}}$, H AHMED $^{\mathrm{d}}$, YS LEPE
}

\begin{abstract}
Summary:
The estimation of foetal birth weight is an important factor in the management of high risk pregnancies. Estimated foetal weight is calculated in the standard routine antepartum evaluation of high risk pregnancies and deliveries. This prospective observational study was done at the Department of Obstetrics and Gynecology in Border Guard Hospital, Peelkhana, Dhaka over a period of 6 months from January 2012 to June 2012. The present study was carried out to compare the accuracy of actual and ultrasonographic estimation of foetal weight at term. Hundred pregnant women at different gestational age from 37 weeks to 40 weeks were selected by simple random sampling. Ultrasonography was done for determination of estimated foetal weight (EFW) at term by using Hadlock method and birth weight was measured just after delivery. Data analysis was done by percentage and paired ' $t$ ' test. The age range of patients were 18-37 years with mean $\pm S D$
\end{abstract}

Introduction:

Accurate estimation of fetal weight is of paramount importance in the management of labour and delivery. ${ }^{1}$ It has long been established that birthweight is a major determinant of infant mortality in the first year of life and that mortality rates are more sensitive to brithweight than gestational age. Hence the importance attached to antenatal birthweight determination. ${ }^{2}$

The use of ultrasound for determination of fetal weight spans over three decades now, with varied attempts at the use of different biophysical parameters. Initial attempts to

a. Dr Lt Col Nahid Reaz Shapla, Head of the Department, Obs and Gynecology, Border Guard Hospital, Peelkhana, Dhaka.

b. Dr Lt Col Mohammad Abdul Aleem, Head of the department ,Anasthiology, Border Guard Hospital , Peelkhana, Dhaka .

c. Dr Lt Col Eva Jesmin, Head of the Department, Paediatrics, BG Hospital, Peelkhana.

d. Dr Hussain Ahmed, Junior consultant, Department of Radiology, BG Hospital Peelkhana, Dhaka .

e. Dr Yasmin Samad Lepe, Consultant, Obs and Gyne, BG Hospital, Dhaka.

Address of Correspondence: Lt Col Nahid Reaz Shapla, Gynaecologist, Border Guard Hospital, Peelkhana, Dhaka, Mobile: 01742181427.

Received: 13 February, 2013

Accepted: 20 December, 2013 is 25.13 \pm 4.46. Among 100 study patients $33 \%$ were nuliparous and $67 \%$ were multiparous. The mean $\pm S D$ of gestational age and actual birth weight is $38.76 \pm 1.09$ and $3.11 \pm 0.391$ respectively. Ultrasound biometric data that includes mean $\pm S D$ biparietal diameter (BPD) in $\mathrm{mm}$, abdominal circumference $(A C)$ in $\mathbf{m m}$ and femur length $(F L)$ in $\mathrm{cm}$ were $90.21 \pm 3.52,327.67 \pm 20.75$ and $7.45 \pm 1.43$ respectively. Mean $\pm S D$ of estimated foetal weight ( $E F W$ ) $\mathrm{Kg}$ was $2.97 \pm 0.53$. Actual birth weight is correlated with the estimated foetal weight and the result was not statistically significant ( $P$ >.05). Calculation of estimated fetal weight by ultrasonography is recommended to make decision about mode of delivery, so that an obstetrician can plan early in high risk cases.

Key words: Estimated foetal weight, Birth weight, Bipari et al diameter abdominal circumference.

(J Banagladesh Coll Phys Surg 2014; 32: 21-25)

estimate fetal weight by ultrasound were made on the basis of measurements of individual single fetal parameters such as the Biparietal Diameter (BPD) or abdominal circumference (AC). Weight estimates obtained by these parameters were found to have high standard deviation up to $11.9 \%$. Subsequent reports demonstrated that accuracy of the estimate was improved by the use of multiple fetal parameters. Further attempts to improve the predictive value of sonography in fetal weight estimation have resulted in the use of more parameters combined. Hadlock et al showed that using femur length (FL) in addition to head measurements and abdominal measurements significantly improved fetal weight estimation. ${ }^{2}$

This study is done to obtain an estimated fetal weight from the fetal parameters and to highlight the predictive value of this procedure by comparing the estimated fetal weight with the actual birth weight.

During the last decade estimated fetal weight has been incorporated into the standard routine antepartum evaluation of high risk pregnancies and deliveries. For instance, management of diabetic pregnancy, vaginal birth after a previous caesarean section and intrapartum management of fetuses presenting by the breech will be greatly influenced by estimated fetal weight. ${ }^{1}$ 
An acurate diagnosis of macrosomia for patients with gestational diabetes can reduce perinatal morbidity as it may assist the physician and staff in deciding the appropriate route of delivery, to prepare for shoulder distocia or to prevent a traumatic injury. Correct EFW values are also important when intrauterine growth is restricted and in preterm labour. ${ }^{3}$

The present study was undertaken to determine the accuracy of birth weight estimation by routine antepartum sonography at term.

\section{Materials and Methods:}

This prospective observational study was carried out in the Department of Obstetric and Gynecology in Border Guard Hospital, Peelkhana, Dhaka over a period of 6 months from January 2012 to June 2012. This study includes 100 pregnant women at term including obstetrical and medical complications (37-40 weeks), reliable date of last menstrual record, regular menstrual cycle, close correlation between menstrual age and clinical gestational age measurements, singleton pregnancy and live born infants without congenital malformation or hydrops. Women not at term, women with multiple pregnancies, advanced labour, antenatal diagnosis of congenital fetal malformation and intrauterine fetal death were excluded from this study.

Verbal consent from each patient was taken. After taking history with particular attention to aspects relevant to the study, clinical examination was done.

Once the diagnosis is confirmed the ultrasound examination was carried out by the same sonologist using 2D and 4D curvilinear probe by GE Voluson 730 Pro Scanner. Measurements were made with calibrated caliper on the machine on frozen images.

Biparietal Diameter (BPD) was made at the level of thalami from outer to inner table of the skull. Abdominal circumference was measured on the outer margin of the abdomen using internal calipers. Femur length measurements were taken by Hadlock method.

Estimated fetal weight is calculated by using standard Hadlock reference table that used biparietal diameter, abdominal circumference and femur length.

Birth weights were measured just after delivery.

Estimated fetal weight, patient demographic data and actual birth weight were recorded on data sheet that was kept separate from the patients chart. Student ' $t$ ' test was done and level of significance was set at $\mathrm{P}<0.05$ (5\%).

\section{Results:}

One hundred pregnant women at term from 37 to 40 weeks gestational age were randomly selected.

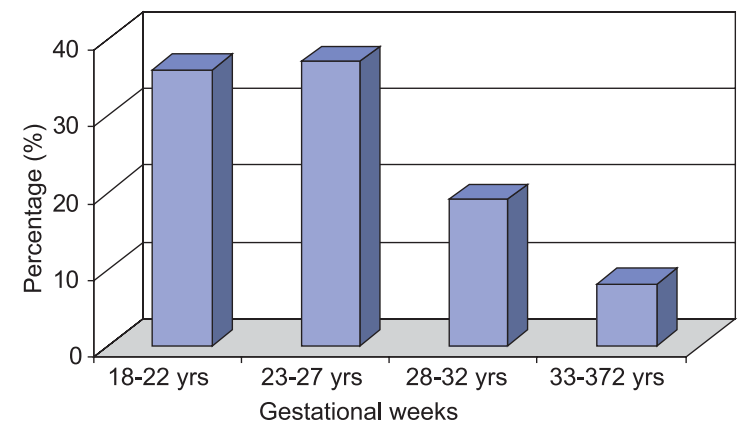

Fig- 1: Age distribution of subjects.

Figure 1 shows age range of the patients were between 18 -37 years with a mean age of $25.13 \pm 4.46$ years.

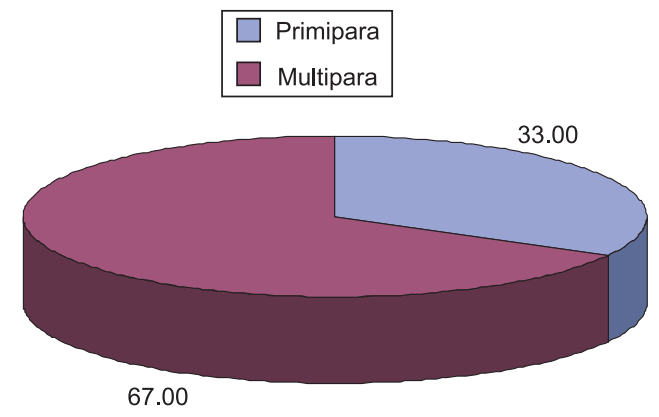

Fig- 2: Distribution of parity.

In figure 2 among 100 patients thirty three percent of gravidas were nulliparous and sixty seven percent were multiparous.

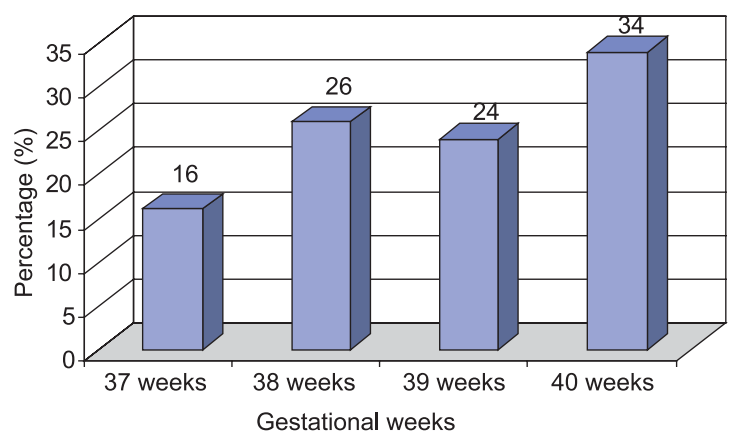

Fig- 3: The distribution of patient by gestational age.

In figure 3 among 100 patients 37 weeks pregnancy were of $16 \%$, 38 weeks pregnancy $26 \%$, 39 weeks pregnancy were of $24 \%$ and 40 weeks pregnancy were of $34 \%$. 
Table-I

Different ultrasonographic biometric data, EFW and birth weight at different gestational age.

\begin{tabular}{lcccc} 
Parameters (Mean \pm SD) & 37 weeks & 38 weeks & 39 weeks & 40 weeks \\
\hline BPD (MM) & $88.8 \pm 3.33$ & $90.2 \pm 3.68$ & $90.4 \pm 3.77$ & $90.8 \pm 3.29$ \\
AC (MM) & $323.0 \pm 22.15$ & $334.8 \pm 18.35$ & $328.3 \pm 22.22$ & $324.0 \pm 20.12$ \\
FL (MM) & $7.3 \pm 0.32$ & $7.4 \pm 1.55$ & $7.5 \pm 1.07$ & $7.6 \pm 1.83$ \\
EFW (kg) & $3.1 \pm 0.37$ & $2.9 \pm 0.42$ & $2.9 \pm 0.69$ & $2.9 \pm 0.57$ \\
Birth weight $(\mathrm{kg})$ & $3.1 \pm 0.51$ & $3.0 \pm 0.31$ & $3.2 \pm 0.34$ & $3.1 \pm 0.42$ \\
\hline
\end{tabular}

\section{Table-II}

Mean biparietal diameter (BPD), abdominal circumference (AC), femoral length (FL) and mean estimated foetal weight (EFW)

\begin{tabular}{lcccc} 
Characteristics & Minimum & Maximum & Mean & Std. Deviation \\
\hline BPD (MM) & 85 & 96 & 90.21 & \pm 3.52 \\
AC (MM) & 293 & 358 & 327.67 & \pm 20.75 \\
FL (MM) & 5.13 & 15.0 & 7.45 & \pm 1.43 \\
EFW (kg) & 1.049 & 4.20 & 2.97 & \pm 0.53 \\
\hline
\end{tabular}

Out of 100 patients BPD were ranging $85 \mathrm{~mm}$ to $96 \mathrm{~mm}$ with mean $90.21 \pm 3.52$, AC ranging $293 \mathrm{~mm}$ to $358 \mathrm{~mm}$ with mean \pm SD of $327.67 \pm 20.75$, FL ranging 5.13 to 15.0 with man \pm SD of $7.45 \pm 1.43$, EFW ranging from $1.049 \mathrm{Kg}$ to $4.20 \mathrm{Kg}$ with mean $\pm \mathrm{SD}$ of $2.97 \pm 0.533$

\section{Table-III}

\begin{tabular}{|c|c|c|}
\hline Birth weight & Number & Percentage \\
\hline$\overline{<2.5 \mathrm{Kg}}$ & 14 & $14 \%$ \\
\hline $2.5-<4 \mathrm{Kg}$ & 73 & $73 \%$ \\
\hline$>4 \mathrm{Kg}$ & 13 & $13 \%$ \\
\hline
\end{tabular}

Among 100 patients $14 \%$ had birth weight $<2.5 \mathrm{Kg}$, $73 \%$ had birth weight of $2.5-<4 \mathrm{Kg}$ and $13 \%$ birth weight had $>4 \mathrm{Kg}$

\section{Table-IV}

Mean $\pm S D$ of gestational age and birth weight after delivery.

\begin{tabular}{lccr} 
Characteristics & Minimum & Maximum & Mean \pm SD \\
\hline Gestational age (Weeks) & 37 & 40 & $38.76 \pm \mathbf{1 . 0 9}$ \\
Birth weight (Kg) & 2.0 & 4.5 & $3.11 \pm \mathbf{0 . 3 9 1}$ \\
\hline
\end{tabular}

Among 100 patients minimum gestational age was 37 weeks and maximum 40 weeks with mean \pm SD of
38.76 \pm 1.09 . Birth weight of newborn after delivery ranging from 2.10 to $4.5 \mathrm{Kg}$ with mean $\pm \mathrm{SD} 3.11 \pm 0.391$.

\section{Table-V}

Discrepancy between mean birth weight and estimated fetal weight including $P$ value.

Ultrasound Mean Birth Mean true P value Estimated fetal weight Weight Kg Birth weight (EFW) Kg -EFW Kg

\begin{tabular}{llll}
$2.97 \pm 0.53$ & $3.11 \pm 0.391$ & 0.07 & $\mathrm{p}>0.05$ \\
\hline
\end{tabular}

Among 100 patients mean EFW 2.97 \pm 0.53 , mean birth weight after delivery $3.11 \pm 0.391$ which shows no significant difference $(\mathrm{P}>0.05)$.

\section{Discussion:}

Accurate estimation of fetal weight has been shown to reduce parinatal mobidity and mortality associated with high risk pregnancy such intrauterine growth restriction and prematurity. ${ }^{2}$ In present study the age range of patients was between 18-37 years with a mean age of $25.13 \pm 4.46$ years. Akinula RA et al observed the age range of patients was between 16-41 years with a mean of 30.7 years. $^{2}$ Akinula S. S. et al showed that mean maternal age was $30.5 \pm 47$ (range $22-41$ ). ${ }^{1}$ In this study $33 \%$ were primigravida and $67 \%$ were multiparous. 
Akinula S. S. et al showed that $35 \%$ gravidas were multiparous and $60 \%$ were multiparous and which $5 \%$ were grand multiparous. ${ }^{1}$ In this study mean gestational age \pm SD of $38.76 \pm 1.09$ with minimum gestational age was 37 weeks and maximum 40 weeks. Akinula S. S. et al observed that gestational age was $38.6 \pm 1.3$ (range 37-42 weeks) which is almost similar to present study. ${ }^{1}$ Akinula RA et al also observed almost the similar findings. ${ }^{2}$ Juozas $\mathrm{K}$. et al found in his study obtained from 5612 pregnant women. Fetal weight was estimated for each fetus using the formulas of Campbell and Wilkin, Shepard, 2 formulas of Hadlock and Merz. The result showed the best was Hadlock formula using 3 fetal biometry parameters. The lowest interclass correlation was found with Shepard formula. ${ }^{4}$ In present study EFW is taken by ultrasound by Hadlock method. In this study EFW at 37 weeks $3.1 \pm 0.37(\mathrm{Kg})$ and actual birth weight $3.1 \pm 0.51(\mathrm{Kg})$ Akinula RA et al observed EFW at 37 weeks by Jadlock mathod mean \pm SD $3290 \pm 123$ and Actual Birth weight $3081 \pm$ SD which is almost similar to present study. ${ }^{2}$ In this study EFW at 38 weeks $2.9 \pm 0.42$ and actual birth weight $3.0 \pm 0.31$ (Kg) Akinula RA et al showed that EFW 3392 \pm 136 and Actual weight is $3338 \pm 385$ which is almost similar with this present study. ${ }^{2}$

In this study at 39 weeks and 40 weeks EFW 2.9 \pm 0.69 and $2.9 \pm 0.57$ respectively and Actual birth weight $3.2 \pm 0.34$ and $3.1 \pm 4.2 \mathrm{Kg}$ respectively which is also similar in the study observed by Aknula RA et al. ${ }^{2}$

After 36 weeks, the rate of weight gain steadily decreases in the normal fetus. ${ }^{5}$ In our study after 37 wks to 40 wks mean EFW (Kg) shows steady decline from $3.1 \pm$. 0.37 to $2.9 \pm 0.57$.

In present study Mean Actual birth weight is 2.10 to 4.5 $\mathrm{Kg}$ with mean \pm SD $3.11 \pm 0.391$ which the mean EFW $2.97 \pm 0.533$. So no significance difference between estimated fetal weight and actual birth weight.

Asrafganjooei $T$ et al observed that the mean actual birth weight was 3329 (SD 443) g while the mean estimated fetal weights by ultrasound and clinical assessment were 3305 (SD 335) 3321 (SD 449). ${ }^{3}$

In one study done in Nigeria showed that clinical estimation of birth weight is as accurate as routine ultrasonographic estimation except in low birth weight babies. Therefore, when the clinical method suggests weight smaller than 2500 g, subsequent sonographic estimation is recommended to wield a better prediction and to further evaluation fetal well-being. ${ }^{1}$ In contrast to this research we found that the accuracy of ultrasound for estimation of fetal weight is significant.

Hisham M. M. et al observed that the mean BPD measurement was $9.1 \pm 0.39 \mathrm{~cm}$, mean $\mathrm{AC}$ was $34.1 \pm 3.0$ $\mathrm{cm}$ and mean FL was $72 \pm 0.36 \mathrm{~cm}$. the mean birth weight was $3418 \pm 541 \mathrm{gm}$. The correlation with actual term birth weight was highest with the formula of Shepard and Hadlock. The formula of Shepard and Hadlock had the minimum mean absolute percentage errors of 0.2 and 1.0 respectively. ${ }^{6}$

In present study mean BPD 90.21 \pm 3.52 , mean AC $327.67 \pm 20.75$, mean FL $7.45 \pm 1.43$ and mean EFW $2.97 \pm 0.53$. In this study the mean discrepancy between true birth weight and estimated fetal weight is 0.07 . In present study, 14\% babies were LBW with mean birth weight $2.97 \pm 0.53$.

The positive predictive value of a sonographic estimate of fetal weight of $<2500 \mathrm{~g}$ is $87 \%$ for preterm fetuses, with a sensitivity of $90 \%$, and the positive predictive value for a sonographic estimate of fetal weight $<1500$ $\mathrm{g}$ is $86 \%$, with a sensitivity of $93 \% .^{7}$ A weight estimate above 4000 grams is associated with a $77 \%$ chance of macrosomia, and a weight above 4500 grams is associated with an $86 \%$ chance of macrosomia. The chance of macrosomia is only $16 \%$ when the weight estimate is less than 4000 grams. $^{8}$

\section{Conclusion}

Low birth weight and excessive fetal weight at delivery both are associated with an increased risk of neonatal complications during labor and the puerperium. Birth weight has predicting value regarding survival and it is a useful parameter in predicting the susceptibility of diseases, future growth and development. In developing countries low birth weight is single most important factor that effects neonatal mortality and morbidity. Thus birth weight has largely been a subject of clinical and epidemiological importance and a target for public health intervention. Ultrasonography is an important tool for estimating fetal weight in uterus. The accuracy of ultrasound estimations of fetal weight before delivery in term pregnancies shows no significant difference with actual birth weight. So calculation of estimated fetal weight by ultrasonography is recommended to make decision about mode of delivery, so that an obstetrician 
can plan early in high risk cases. Further large scale study is needed to establish the requirement of ultrasonography in each term pregnant women for estimation of fetal weight.

\section{Reference:}

1. Akinola SS, Oluwafemi K, Ernest OO, Oluwabemiga OA, Salami SS. Clinical versus sonographic estimation of foetal weight in southwest Nigeria. J health pupul nutr 2007; 25(1) : 14-23.

2. Akinola RA, Akinola OI, Oyekan OO. Sonography in fetal birth weight estimation. Educational research and review 2009; 4(1) : 16-20.

3. Ashrafgan gooei T, Naderi T, Eshrati B, Babapoor N. Accuracy of Ultra sound clinical and maternal estimates of birth weight in term women. Esterm mediterrean health Journal 2010 ; 16(3) : 313-317.
4. Juozas K, Tilo B, Joset W, Renate H. Ultrasonographic fetal weight estimation : Accuracy of formulas and accuracy of examiners by birth weight from 500 to 5000 gm. J Perinal Med 2004 ; 33 : 155-161.

5. Carol B. Benson, Peter M. Doubilet. Fetal Measurements Normal and Abnormal fetal growth, $3^{\text {rd }}$ ed, Carol M. Rumack, Stephanie R. Wilson, J. Wiilliam Charboneau etal 2005 ; P1503.

6. Hisham MM, Sarath W, Mutaria E, Johr RS. Ultrasonic estimation of fetal weight at term : An evaluation of eight formula. J Obstetrics and Gynocology 2005;31(5) : 409-413.

7. Gerard G Nahum, Cari V Smith. Estimation of Fetal Weight. Updated : Oct 17, 2011 ; Medscape : 1-42.

8. Benson CB, Doubiler PM, Saltzman DH: Sonographic determination of fetal weights in diabetic pregnancies. Am J Obster Gynecol 1987 ;156:441-444. 